\title{
Analisa Kehilangan Minyak (Oil Losses) Pada Proses Produksi Di Pt X
}

\author{
Arif Nurrahman $^{1 *}$, Edwin Permana ${ }^{2}$, Azra Musdalifah ${ }^{3}$ \\ ${ }^{1}$ Politeknik Energi dan Mineral Akamigas, Jalan Gajah Mada No. 38 Cepu, Blora, Jawa Tengah \\ ${ }^{2,3}$ Program Studi Kimia Industri, Fakultas Sains dan Teknologi, Universitas Jambi, Jambi, Indonesia, Jl. Jambi-Ma. Bulian KM15 Mendalo \\ Darat Jambi 36361 \\ *Email: anurrahman@esdm.go.id
}

\begin{abstract}
Palm oil is one of the crops that produce crude palm oil (CPO). Losses or loss of production is generally a natural thing in the palm oil processing process. Oil losses are the loss of the amount of oil that should be obtained from the results of a process but the oil cannot be obtained or is lost. The loss rate for palm oil is the amount of oil that is not taken up in the processing. The oil that is not taken is partly wasted into the boiler as fuel (oil from fiber). Oil losses are the loss of the amount of oil that should be obtained from the results of a process but the oil cannot be obtained or is lost. In testing oil losses using the socket extraction method. Soxlet extraction is a continuous extraction technique using a soxhlet, with the principle of distillation of solvent from the flask to the cooler, then dripping wet and immersing the sample located in the center of the soxlet apparatus.
\end{abstract}

Keywords : CPO; Oil Losses; Palm Oil; Production

\section{Pendahuluan}

Perkebunan kelapa sawit menghasilkan tandan buah segar (TBS). TBS diproses oleh pabrik kelapa asawit (PKS) utuk menghasilkan minyak sawit mentah (CPO) dan produk turunan lainnya. Salah satu karakteristik TBS adalah mudah rusak. Pascapanen, dalam 48 jam TBS harus diolah untuk mengurangi kerusakan berupa kehilangan kandungan minyak. Produktivitas yang tinggi menjadikan kelapa sawit kompetitif sebagai alternatif minyak yang dapat digunakan oleh industri makanan, kosmetik, produk kesehatan, biofuel dan biodiesel (Stephanie et al., 2018).

Tanaman kelapa sawit merupakan komoditi andalan indonesia yang perkembangannya demikian pesat. Kelapa sawit merupakan salah satu tanaman penghasil minyak nabati crude palm oil (CPO), tanaman ini sangat banyak ditanam dalam perkebunan di Indonesia terutama di pulau sumatera, Kalimantan, Sulawesi dan papua. Selain menghasilkan crude palm oil (CPO) juga menghasilkan limbah yang sangat banyak berupa limbah padat dan cair. Limbah padat berupa tandan kosong, cangkang dan fiber (Haryanti et al., 2014).

Minyak kelapa sawit (CPO) merupakan minyak nabati yang didapatkan dari daging dan serabut buah (mesocarp) yang mengandung banyak minyak, umumnya dari spesies elaesis guineensis. Minyak sawit termasuk minyak yang memiliki kadar lemak jenuh yang tinggi, terdiri atas asam lemak yang teresterfikasi dengan gliserol. Ketika pemrosesan sebagian minyak sawit mengalami oksidasi. Dalam proses pengolahan sawit, perusahaan selalu berupaya untuk mengoptimalkan jumlah rendemen CPO. Salah satu sistem manajemen peruahaan yang ditetapkan untuk mendapatkan jumlah rendemen yang optimal adalah menekan terjadinya kehilangan minyak (oil losses) pada CPO selama proses produksi. Kehilangan minyak (oil losses) yang terjadi pada setiap stasiun proses pengolahan minyak' kelapa sawit dikarenakan berbagai faktor. Kadar oil losses yang tinggi mempengaruhi efisiensi produksi pengolahan, menimbulkan kerugian, hal ini disebabkan peralatan yang tidak memiliki kemampuan dan kapasitas desain yang optimal (Irwansyah et al., 2019).

Losses atau kehilangan produksi umumnya merupakan hal yang wajar dalam proses pengolahan kelapa sawit. Oil losses merupakan kehilangan jumlah minyak yang seharusnya diperoleh dari hasil suatu proses namun minyak tersebut tidak dapat diperoleh atau hilang. Angka kehilangan/kerugian minyak sawit merupakan banyaknya minyak yang tidak terambil pada proses pengolahan. Minyak yang tidak terambil ini sebagian terbuang ke boiler sebagai bahan bakar (minyak dari fibre). Oil losses merupakan kehilangan jumlah minyak yang seharusnya diperoleh dari hasil suatu proses namun minyak tersebut tidak dapat diperoleh atau hilang. Pada pengujian oil losses menggunakan metode ekstraksi soklet. Ekstraksi adalah proses penarikan suatu zat dari sumber bahan (campuran) dengan pelarut cair sehingga zat terpisah dari komponen lain yang tidak dapat larut dalam pelarut. Campuran antara fluida padat dan cair sulit untuk dipisahkan, baik secara mekanik maupun termal. Hal ini disebabkan karena zat penyusunnya saling larut, sensitive terhadap panas erat, peka terhadap panas, perbedaan karakter fisiknya sangat kecil, dan konsentrasinya sangat kecil (Utomo, 2016).

Ekstraksi soklet merupakan alat yang digunakan untuk mengekstraksi suatu senyawa dari material padatnya. Dalam sokhlet akan digunakan pelarut yang berfungsi melarutkan senyawa yang akan diekstraksi. Ekstraksi sokhlet akan menghemat penggunaan pelarut, karena dapat digunakan berulang-ulang. Senyawa yang telah terlarut tidak akan ikut menguap saat dipanaskan karena suhu reflux telah diatur di bawah titik didih senyawa (Ethica, 2020).

Berdasarkan latar belakang permasalahan yang ada, maka dalam kegiatan analisa ini dapat diambil perumusan masalah, Bagaimana cara menganalisis kehilangan minyak (oil losses), penyebab tingginya oil losses, serta bagaimana mengatasi tingginya oil losses pada setiap sampel.

\section{Metodologi Penelitian}

\subsection{Bahan san Peralatan}

Bahan yang digunakan dalam kegiatan analisa oil losses berupa bahan padat seperti press fibre, empty bunch dan nut dan bahan cair berupa final effluent dan heksan. Adapun alat yang digunakan dalam analisa oil losses ini yaitu Crystallizing Dish, evaporating dish, desikator, Timbal, Flasck Bottom, Analitytical Balance, oven dan alat ekstraksi soklet. 


\subsection{Metode Analisis}

Metode yang digunakan untuk penentuan Analisa Kehilangan Minyak (Oil Losses) Pada Proses Produksi yakni secara ekstraksi soklet yang dimana ekstralsi soklet digunakan untuk memisahkan dua senyawa berbeda seperti heksan dan minyak

\subsection{Prinsip Kerja}

Prinsip soklet yaitu penyaringan yang dilakukan secara berulang sehinggan hasil yang didapatkan sempurna dan pelarut yang digunakan untuk mengekstraksi relative sedikit. Prinsip soklet pada percoban ini memisahkan antara minyak dan heksan.

\subsection{Perhitungan}

Adapun rumus mencari oil losses sebagai berikut :

a. Empty Bunch

1) \% Oil Losses pada on sampel:

Adapun rumus untuk mencari oil losses sebagai beikut:

Berat sampel basah $=$ Berat wadah + sampel basah berat wadah kosong

Berat sampel kering $=$ Berat wadah + sampel.

2) \% Oil Losses on TBS

Empty Bunch $=\%$ O/WM x $22 \%$

Catatan: $22 \%$ adalah $\%$ material balace pada empty bunch

b. Nut

1) \% Oil Losses pada on sampel:

Adapun rumus untuk mencari oil losses sebagai beikut: Berat sampel basah $=$ Berat wadah + sampel basah berat wadah kosong

Berat sampel kering $=$ Berat wadah + sampel kering berat wadah kosong

2) \% Oil Losses on TBS

$N U T=\%$ O/WM x $12 \%$

Catatan: $12 \%$ adalah \% material balance pada NUT

c. Final Effluent

1) \% Oil Losses pada on sampel:

Adapun rumus untuk mencari oil losses sebagai beikut:

Berat sampel basah $=$ Berat wadah + sampel basah berat wadah kosong

Berat sampel kering $=$ Berat wadah + sampel kering berat wadah kosong

2) \% Oil Losses on TBS

Final Effluent $=\%$ O/WM x $60 \%$

Catatan: $60 \%$ adalah $\%$ material balance pada Final Effluent

d. Press Fibre

1) \% Oil Losses pada on sampel: Adapun rumus untuk mencari oil losses sebagai beikut:

Berat sampel basah $=$ Berat wadah + sampel basah berat wadah kosong

Berat sampel kering $=$ Berat wadah + sampel kering berat wadah kosong

$\mathrm{O} / \mathrm{WM}=$ berat sampel diekstraksi \& sudah dikeringkan-berat botol flasck botto

$$
\text { berat sampel basah }
$$

2) \% Oil Losses on TBS

Press Fibre = \% O/WM x 12\%

Catatan: $12 \%$ adalah $\%$ material balance pada fibre

\subsection{Prosedur Pengujian}

a. Bahan Padat
1) Ditimbang crystallizing dish kosong dan diberi label

2) Dicatat berat crystallizing dish kosong

3) Dimasukkan sampel kedalam crystallizing dish sebanyak 10gr

4) Dimasukkan kedalam oven dengan suhu $135^{\circ} \mathrm{C}$ selama \pm 2 jam

5) Dimasukkan sampel yang telah diovenkan tadi kedalam desikator sampai dingin

6) Ditimbang sampel kering yang telah dingin

7) Dicatat berat sampel yang telah kering

8) Digulung sampel dengan tisu dan dimasukkan kedalam paper thimble

9) Ditimbang flask bottom kosong dan diberi label

10)Dicatat berat flask bottom kosong

11)Dimasukkan sampel yang di paper thimble tadi ke dalam soxhlet extractor

12)Diletakkan flask bottom ke heating mantle dan dimasukkan heksan $3 / 4$ kedalam flask bottom

13) Dirangkai alat soxhlet dan dialirkan air pada kondensor pada alat soxhlet

14)Dihidupkan heating mantle

15)Dilakukan ekstraksi dengan memanaskan sampel selama \pm 4 jam sampai seluruh minyak terekstrak

16)Dipisahkan heksan dengan minyaknya

17)Dimasukkan ke oven \pm 1 jam

18)Didinginkan

19)Ditimbang dan dicatat berat minyak yang ada di flask bottom

\section{b. Bahan Cair}

1) Ditimbang evaporating dish kosong dan diberi label

2) Dicatat berat evaporating dish kosong

3) Dimasukkan sampel kedalam evaporating dish sebanyak $20 \mathrm{gr}$

4) Dimasukkan kedalam oven dengan suhu $135^{\circ} \mathrm{C}$ selama \pm 4 jam

5) Didinginkan sampel yang telah diovenkan tadi

6) Ditimbang sampel kering yang telah dingin

7) Dicatat berat sampel kering

8) Digulung sampel dengan tisu dan dimasukkan kedalam paper thimble

9) Ditimbang flask bottom kosong dan diberi label

10) Dicatat berat flask bottom kosong

11)Dimasukkan sampel yang di paper thimble tadi ke dalam soxhlet extractor

12)Diletakkan flask bottom ke heating mantle dan dimasukkan heksan 3/4 kedalam flask bottom

13)Dirangkai alat soxhlet dan dialirkan air pada kondensor pada alat soxhlet

14) Dihidupkan heating mantle

15)Dilakukan ekstraksi dengan memanaskan sampel selama \pm 4 jam sampai seluruh minyak terekstrak

16) Dipisahkan heksan dengan minyaknya

17)Dimasukkan ke oven \pm 1 jam

18) Didinginkan

9) Ditimbang dan dicatat berat minyak yang ada di flask bottom

\section{Hasil Dan Pembahasan}

\subsection{Preparasi Sampel}

Dalam penelitian ini, tahapan awal dari sebuah proses analisis adalah preparasi sampel dari sampel yang akan diuji. Tahapan preparasi sampel yang dimaksud yaitu dimulai dengan proses pengambilan sampel dipabrik, sampel diambil 
setiap 2 jam setelah start proses. Setelah itu sampel tadi dikomposit dan diquarting dan dimasukkan kedalam kantong plastik berlabel. Manfaat dari mengkomposit dan mengquartingkan sampel yaitu supaya sampel yang diambil setiap 2 jam tadi akan bercampur dengan rata sehingga bisa mengurangi tingginya oil losses yang didapat. Setelah itu sampel tersebut diuji \% O/WM dan \% on TBS untuk mengetahui hasil oil losses yang didapat.

\subsection{Pengujian Sampel}

Pada analisis oil losses ini digunakan ekstraksi soklet. Penggunaan ekstraksi soklet ini dikarenakan ada analisis oil losses tersebut menghasilkan minyaak sebagai hasil akhir sampel. Ekstraksi soklet juga akan menghemat penggunaan pelarut, karena dapat digunakan berulang-ulang. Senyawa yang telah terlarut tidak akan ikut menguap saat dipanaskan karena suhu refluks telah diatur dibawah titik didh senyawa.

\subsection{Hasil Analisa Oil Losses}

Oil losses adalah kehilangan jumlah minyak yang seharusnya diperoleh dari hasil suatu proses namun minyak tersebut tidak dapat diperoleh atau hilang. Angka kehilangan/kerugian minyak sawit merupakan

banyaknya minyak yang tidak terambil pada proses pengolahan. Pada analisa oil losses ini menggunakan metode ekstraksi soklet. Ekstraksi soklet adalah ekstraklsi yang memisakan antara minyak dan heksan. prinsip ekstraksi pada oil losses tersebut adalah memisahkan antara dua zat dengan massa jenis berbeda yaitu minyak dan heksan.

Adapun hasil pengamatan yang diperoleh dapat dilihat pada tabel berikut.

Tabel 1 :Data pengambilan sampel Oil Losses di PT X

\begin{tabular}{|c|c|c|c|c|c|c|c|c|c|c|}
\hline \multirow{3}{*}{ No } & \multirow{3}{*}{$\begin{array}{c}\text { Waktu } \\
\text { pengam- } \\
\text { bilan sampel } \\
\text { (Hari) }\end{array}$} & \multicolumn{8}{|c|}{ Sampel Oil Losses } & \multirow{3}{*}{$\begin{array}{c}\text { Total } \\
\text { losses } \\
\text { /TBS } \\
(1,60) \\
\%\end{array}$} \\
\hline & & \multicolumn{2}{|c|}{ Empty Bunch } & \multicolumn{2}{|c|}{ Press Fibre } & \multicolumn{2}{|c|}{ NUT } & \multicolumn{2}{|c|}{ Final Effluent } & \\
\hline & & $\begin{array}{c}(<2) \\
\%\end{array}$ & $\begin{array}{c}(0,44) \\
\%\end{array}$ & $\begin{array}{c}(<4) \\
\%\end{array}$ & $\begin{array}{c}(0,48) \\
\%\end{array}$ & $\begin{array}{c}(<0,70) \\
\%\end{array}$ & $\begin{array}{c}(0,084) \\
\%\end{array}$ & $\begin{array}{c}(<1) \\
\%\end{array}$ & $\begin{array}{c}(0,60) \\
\%\end{array}$ & \\
\hline 1 & 1 & 2,35 & 0,51 & 4,14 & 0,49 & 0,68 & 0,081 & 1,05 & 0,63 & 1,71 \\
\hline 2 & 2 & 2,24 & 0,49 & 3,11 & 0,37 & 0,68 & 0,081 & 1,01 & 0,60 & 1,54 \\
\hline 3 & 3 & 1,71 & 0,37 & 3,79 & 0,45 & 0,70 & 0,084 & 1,02 & 0,61 & 1,51 \\
\hline 4 & 4 & 1,97 & 0,43 & 3,71 & 0,43 & 0,70 & 0,084 & 0,97 & 0,58 & 1,52 \\
\hline 5 & 5 & 1,39 & 0,30 & 3,90 & 0,46 & 0,66 & 0,079 & 1,01 & 0.60 & 1,43 \\
\hline 6 & 6 & 2,06 & 0,45 & 4 & 0,48 & 0,69 & 0,082 & 0,92 & 0,55 & 1,56 \\
\hline 7 & 7 & 2,59 & 0,56 & 4,52 & 0,54 & 0,66 & 0,079 & 0,91 & 0,54 & 1,71 \\
\hline 8 & 8 & 2,04 & 0,44 & 3,99 & 0,48 & 0,69 & 0,082 & 0,97 & 0,58 & 1,58 \\
\hline 9 & 9 & 3,07 & 0,67 & 3,99 & 0,48 & 0,68 & 0,081 & 0,87 & 0,52 & 1,75 \\
\hline 10 & 10 & 2,12 & 0,46 & 4,16 & 0,48 & 0,15 & 0,018 & 0,88 & 0,52 & 1,47 \\
\hline 11 & 11 & 1,75 & 0,38 & 3,26 & 0,40 & 0,57 & 0,068 & 1,04 & 0,62 & 1,46 \\
\hline 12 & 12 & 2,04 & 0,45 & 4 & 0,48 & 0,53 & 0,063 & 0,94 & 0,56 & 1,55 \\
\hline 13 & 13 & 2,00 & 0,44 & 3,96 & 0,48 & 0,69 & 0,082 & 0,70 & 0,42 & 1,42 \\
\hline 14 & 14 & 1,65 & 0,36 & 4,15 & 0,49 & 0,67 & 0,080 & 0,53 & 0,31 & 1,24 \\
\hline 15 & 15 & 3,73 & 0,74 & 4,18 & 0,50 & 0,58 & 0.069 & 0,89 & 0,53 & 1,83 \\
\hline \multicolumn{2}{|c|}{ Rata - rata } & & & & & & & & & 1,55 \\
\hline
\end{tabular}

Dari data Tabel 1, secara keseluruhan total losses produksi masih dibawah standar atau masih dalam batas terkendali. Berdasarkan dari hasil data diatas total losses tersebut memenuhi kebutuhan pelanggan. Namun jika dilihat perparameter sumber losses kecendrungan masih ada yang diatas

standar meskipun tidak secara signifikan. Adapun parameter yang masih diatas standar diantaranya seperti empty bunch, press fibre dan final effluent (sludge).

\section{a. Empty Bunch (\%)}

Empty bunch merupakan tandan buah kelapa sawit gunanya sebagai tempat terletaknya brondolan (buah sawit), biasanya empty bunch keluar setelah melewati proses threshing. Empty bunch memiliki fisik yang berbentuk serat.

Dari hasil uji oil losses dengan sampel empty bunch dapat dilihat pada grafik.

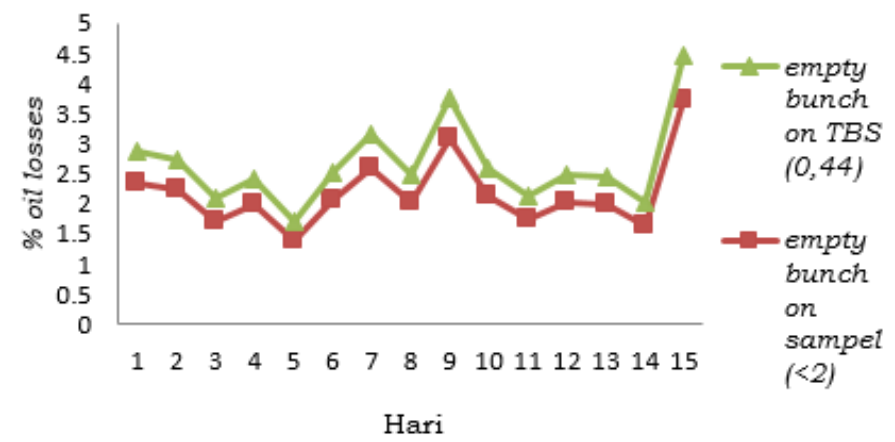

Gambar 1. \% oil losses pada empty bunch

Berdasarkan gambar 1 diatas ditunjukkan bahwa oil losses yang didapatkan masih tinggi atau masih diatas standar oil losses yang ditetapkan perusahaan yang dimana jika oil losses tinggi akan mempengaruhi hasil rendemen.

Berikut faktor penyebab masih tingginya oil losses pada empty bunch:

1. Faktor bahan baku

Buah yang diterima masih ada buah restan, buah restan mengalami penyerapan minyak dan buah yang disiram kelebihan cairan atau evaporasi sehingga mempengaruhi janjangan.

2. Faktor Sumber Daya Manusia (SDM) 
Pada waktu perebusan disamaratakan buah restan dengan buah yang fress dengan waktu 90 menit.

Oil losses pada empty bunch akan tetap ada meskipun dengan berondolan normal. Minyak yang terserap di janjangan berasal dari spiklet brondolan yang direbus sehingga hal ini menyebabkan terjadi oil losses empty bunch. Spiklet berondolan berfungsi sebagai tempat pengeluaran kandungan air di dalam berondolan akan tetapi pada saat perebusan di stasiun sterilizer dengan tekanan dan temperatur yang tinggi bisa mengakibatkan viskositas minyak akan menurun sehingga mengakibatkan minyak keluar dari spiklet. Akan tetapi oil losses yang terjadi tidak terlalu tinggi. Kulit berondolan berfungsi untuk melindungi minyak yang terkandung di dalam mesocarp agar tidak keluar pada saat perebusan berlangsung. Jika kulit berondolan mengalami lecet pada saat perebusan berlangsung dengan tekanan dan temperatur yang tinggi bisa mengakibatkan viskositas minyak akan menurun sehingga mengakibatkan mengecilnya molekul-molekul minyak. Hal ini mengakibatkan terjadinya emulsi dimana air dan minyak sulit dipisahkan. Minyak tersebut akan keluar karena adanya lecet pada buah sehingga minyak akan diserap oleh janjangan sehingga mengakibatkan oil losses pada empty bunch. Semakin tinggi persentase lecet pada buah maka persentase oil losses juga akan semakin tinggi. Buah restan adalah buah yang diterima pada hari itu tetapi diolah di hari selanjutnya. Kondisi ini mengakibatkan kandungan air di dalam janjangan akan berkurang sehingga serabut yang terdapat pada janjangan kering sehingga menimbulkan rongga-rongga udara. Sehingga pada saat janjangan direbus maka serabut akan menyerap air. Oleh karena itu, pabrik harus mengendalikan buah restan setiap harinya dengan membatasi buah restan (rantawi, 2017).

\section{b. Press Fibre}

Press Fibre adalah pemisahan mesocrap menjadi fiber dari NUT di proses pengepresan.

Dari hasil uji oil losses dengan sampel Nut dapat dilihat pada grafik.

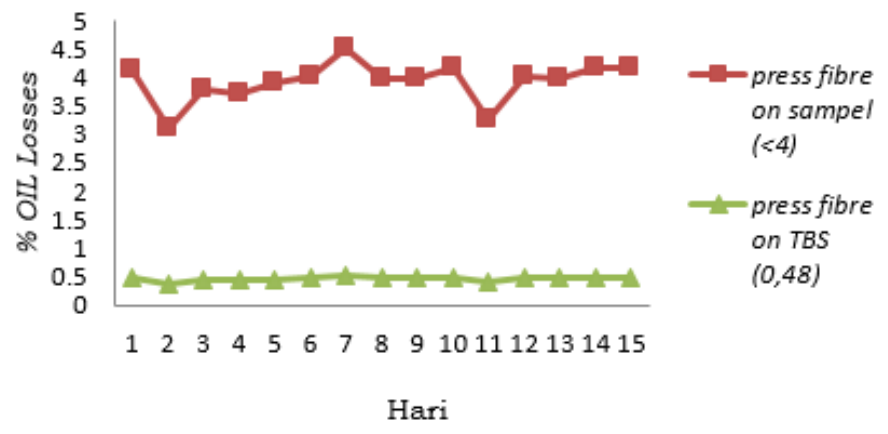

Gambar 2. \% oil losses pada Press Fibre

Dari grafik diatas persentase oil losses pada press fibre masih ada yang melewati standar on sampel yang telah ditetapkan oleh PT X yaitu standar on sampel pada press fibre adalah <4. Berikut beberapa faktor penyebab tingginya oil losses pada empty bunch:

1. Faktor bahan baku

Buah pada fraksi mentah akan sulit diaduk di digester sehingga pada pengempaan kehilangan minyak masih terdapat dalam ampasnya.

2. Faktor alat

Pelumatan dalam digester tidak sempurna, umpan digester kurang dari $3 / 4$ sehingga pelumatan tidak sempurna

\section{Faktor Sumber Daya Manusia (SDM)}

Kurangnya pengecekan

\section{c. Nut}

NUT merupakan salah satu komponen yang terdapat pada TBS (Tandan Buah Segar). Pada pengujian oil losses ini, nut yang digunakan ialah bagian cangkang.

Dari hasil uji oil losses dengan sampel Nut dapat dilihat pada grafik.

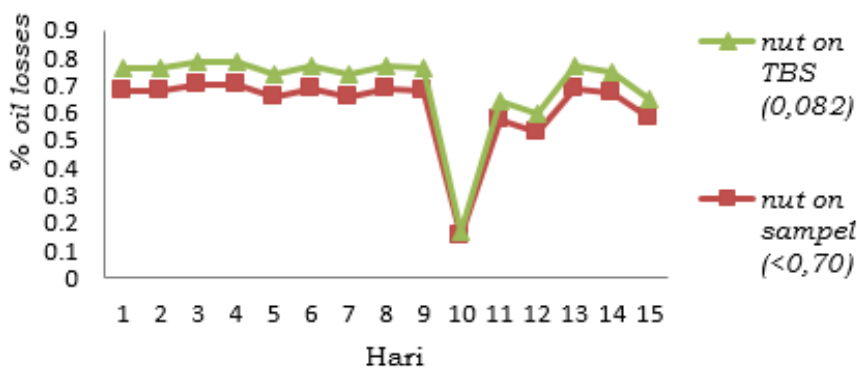

Gambar 3. \% oil losses pada Nut

Dari grafik diatas persentase oil losses pada $N U T$ (cangkang) masih batas standar karena NUT berbanding lurus dengan fiber.

Berikut beberapa faktor penyebab tingginya oil losses pada $N U T$ :

1. Faktor bahan baku

Buah pada fraksi mentah akan sulit diaduk di digester sehingga pada pengempaan kehilangan minyak masih terdapat dalam ampasnya dan biji.

2. Faktor alat

Pencacahan dan Pelumatan dalam digester tidak sempurna, sebagian daging buah tidak lepas dari biji sehingga menyebabkan proses pengempaan tidak sempurna dan kehilangan minyak pada ampas dan biji bertambah.

3. Faktor SDM

Kurangnya pengecekan. Beberapa hal yang menyebabkan kadar nut pecah tinggi antara lain adalah Proses perebusan yang kurang masak, sehingga pada saat proses digester sulit terpisah antara daging buah dengan biji, dan kerja press semakin sulit, tekanan press yang terlampau tinggi serta kondisi kerapatan cones dan press cage terlalu rapat. Tekanan terlalu rendah akan mengakibatkan ampas press basah sehingga kehilangan minyak (losses) akan tinggi serta pada proses pengolahan biji akan mengalami kesulitan. Sedangkan jika tekanan terlalu tinggi akan mengakibatkan kehilangan minyak (losses) pada ampas press menjadi rendah tetapi kadar inti pecah bertambah dan kerugian inti akan bertambah. Tekanan hidrolik yang terlalu tinggi mengakibatkan kadar inti pecah dan kerugian inti bertambah, dan bila tekanan hidrolik terlalu rendah mengakibatkan cake basah, kehilangan minyak pada ampas dan biji bertambah, pemisahan ampas dan biji tidak sempurna dalam proses di cake breaker conveyor dan bahan bakar ampas kering yang dapat menyebabkan pembakaran di boiler tidak sempurna (Hikmawan et al., 2020).

\section{d. Final Effluent}

Dari hasil uji oil losses dengan sampel final effluent dapat dilihat pada grafik: 


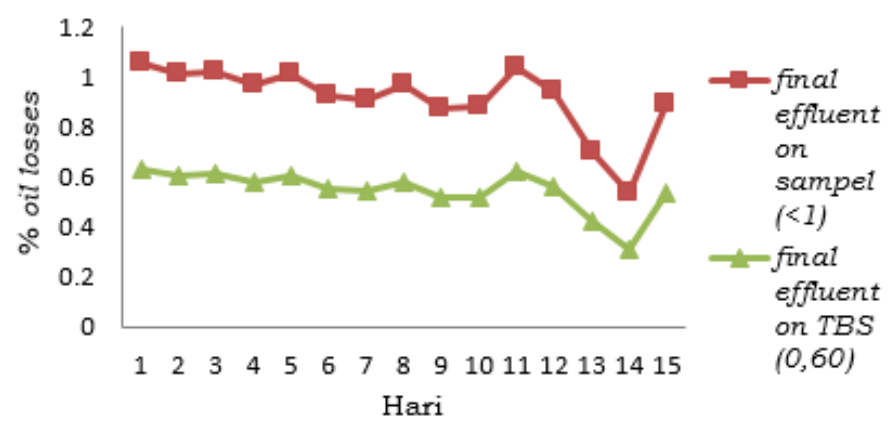

Gambar 4. \% oil losses pada Final Effluent

Dari grafik diatas persentase oil losses pada Final Effluent (Sludge) masih ada yang melewati standar on sampel yang telah ditetapkan oleh PT X yaitu standar on sampel pada NUT $<1$.

Berikut beberapa faktor penyebab tingginya oil losses pada Final Effluent:

1. Faktor alat

Alat centrifuge Terjadinya oil losses tinggi pada final effluent karena kurang efesiensi kinerja pada alat yang bisa menyebabkan oil losses tinggi pada final effluent (sludge). Pada saat pencuci nodzel masih ada pasir yang tertinggal sehingga menyebabkan penyumbatan pada lubang nodzel dan sering terjadinya kebocoran pipa pada centrifuge.

2. Faktor SDM

Pengutipan di bak penampungan final effluent tidak rutin dilakukan sehingga bisa menyebabkan tingginya oil losses.

Limbah cair berasal dari sisa pemisisahan di fat fit yang kemudian di pompa ke kolam limbah. Limbah panas akan masuk dulu ke kolam 1 yaitu cooling pond untuk didinginkan terlebih dahulu ke suhu ruang karena keluaran fat fit bersuhu sekitar $70^{\circ} \mathrm{C}$.

Menurut (Sitorus dan Mardina) 2020. Fat Pit merupakan bak penampungan hasil pemisahan minyak dan pengotornya atau sludge sebelum dikirim ke kolam limbah, fat fit desain mampu memanfaat sisa minyak yang ada didalam sludge dengan memanaskan sludge ke suhu $80-95^{\circ} \mathrm{C}$ sehinga di bagian atas diperoleh minyak kotor yang akan di transfer masuk kembali ke dalam CST sedangkan pada fraksi bawah akan dibuang langsung ke kolam limbah. Sampel ini diambil melalui aliran bawah yang akan dikirim ke kolam limbah. Nilai final effluent bisa menjadi patokan apakah proses klarifikasi minyak sawit berjalan dengan baik dimana klarfikasi meliputi sand tank, rotary drum, CST, oil tank, sludge tank serta decanter. penyebab tingginya oil losses ini menunjukan kandungan minyak yang masih sangat tinggi berada pada sludge hasil proses klarifikasi jika perbandingan antara kotoran serta minyak dimana lebih banyak minyak maka kerja dari fat pit tidak akan optimal dan menyebabkan minyak akan banyak terbuang ke kolam limbah. penyebab lain dari tingginya oil losses pada final effluent adalah suhu fat pit yang tidak memenuhi standart atau berada di bawah standart sehingga minyak, air dan kotoran tidak terpisah dengan baik.

\section{Kesimpulan}

Dari pembahasan yang telah di jelaskan dapat di tarik kesimpulan sebagai berikut.

1. Penentuan Oil Losses (Kehilangan minyak) pada proses produksi kelapa sawit di setiap sampel seperti Empty Bunch, Press Fibre, Nut, dan Final Effluent dalam garis besar ialah sama yaitu dengan mengambil sampel setiap 2 jam setelah start, setiap sampel dari masing-masing stasiun tersebut diquarting dan dikompositkan lalu di masukkan kedalam kantong plastik yang berlabel yang kemudian dilakukan ekstraksi untuk menghitung persentase Oil Losses.

2. Tingginya tingkat kehilangan minyak disebabkan oleh beberapa faktor yaitu dari bahan baku, alat dan manusia.

\section{Daftar Pustaka}

Ethica, S. N. 2020. Buku Ajar Teori Kimia Analitik Teknologi Laboratorium Medis. Yogyakarta: DEEPUBLISH.

Fauzi, Y., Widyastuti, Y. E., Satyawibawa, I., dan Paeru, R. H. 2012. Kelapa Sawit. Jakarta: Penebar Swadaya.

Febrianto, E. B., Gunawan, H., dan Sirait, N. V. 2019. Karakteristik Morfologi Kelapa Sawit (Elaeis guineensis Jacq.) Varietas DyxP Dumpy dengan Pemberian Asam Humat pada Media Tanah Salin di Main Nursery. Jurnal Bernas Agricultural Research, Vol.15(2):103-120.

Haryanti, A., Norsamsi, Sholiha, P. S., dan Putri, N. P. 2014. Studi Pemanfaatan Limbah Padat Kelapa Sawit. Jurnal Konversi , vol.3(2):57-66.

Hikmawan, O., Naufa, M., dan Taringan, E. A. 2020. Pengaruh Tekanan pada Stasiun Screw Press Pabrik Pengolahan Kelapa Sawit Terhadap Kehilangan Minyak dalam Ampas Press. Jurnal Teknik dan Teknologi, Vol.15(29):36-43.

Irwansyah, D., Erliana, C. I., dan Manurung, W. M. 2019. Analisis Kehilangan Minyak (Oil Losses) pada Crude Palm Oil dengan Metode Statistical Proses Control. Jurnal SNTI, Vol.1(1):14-15.

Pahan, I. 2008. Panduan Lengkap Kelapa Sawit. Jakarta: Penebar Swadaya.

Rantawi, A. B. 2017. Pegaruh Kualitas Buah yang Diolah Terhadap Daya Serap Janjangan Kosong dengan Variabel Berondolan. Jurnal Citra Widya Edukasi, Vol.9(3):223-228.

Sitorus, Y. R., dan Mardina, V. 2020. Karekteristik Kimia dari Pengolahan Limbah Cair Kelapa Sawit PTPN Y. Jurnal Enviscience, Vol.2(2):58-66.

Stepnanie, H., Tinaprilla, N., dan Rifin, A. 2018. Efisiensi Pabrik Kelapa Sawit di Indonesia . Jurnal Agribisnis Indonesia , vol.6(1):27-36.

Utomo, S. 2016. Pengaruh Konsentrasi Pelarut (n-Heksan) Terhadap Rendemen Hasil Ekstraksi Minyak Biji Alpukat Untuk Pembuatan Krim Pelembab Kulit. Jurnal Konversi , Vol.5(1):39-47. 